\title{
Introducing a new prognostic instrument for long-term mortality prediction in COPD patients: the CADOT index
}

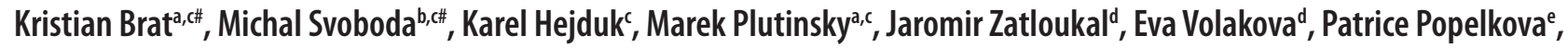 \\ Barbora Novotna ${ }^{\mathrm{f}}$, Dita Engova ${ }^{\mathrm{g}}$, Frits M.E. Franssen, ${ }^{\mathrm{h}, \mathrm{k}}$, Lowie E.G.W. Vanfleteren', Martijn A. Spruit ${ }^{\mathrm{h}, \mathrm{j}, \mathrm{k}}$, Vladimir Koblizek'
}

Objectives. The BODE (BMI, Obstruction - FEV , Dyspnoea - mMRC, Exercise - 6-MWT) and the ADO (Age, Dyspnoea - $\mathrm{mMRC}$, Obstruction - FEV ) indices are widely used prognosis assessment tools for long-term mortality prediction in COPD patients but subject to limitations for use in daily clinical practice. The aim of this research was to construct a prognostic instrument that prevents these limitations and which would serve as a complementary prognostic tool for clinical use in these patients.

Methods and Participants. The data of 699 COPD subjects were extracted from the Czech Multicentre Research Database (CMRD) of COPD patients (the derivation cohort) and analysed to identify factors associated with the longterm risk of mortality. These were entered into the ROC analysis and reclassification analysis. Those with the strongest discriminative power were used to construct the new index (CADOT). The new index was validated on 187 patients of the CIROCO+ cohort (Netherlands; the validation cohort).

Results. The CADOT was constructed by adding two newly identified prognosis-determining factors, chronic heart failure (CHF) and $\mathrm{TL}_{\mathrm{CO}^{\prime}}$ to the $\mathrm{ADO}$ index. In a head-to-head comparison, the CADOT index showed highest c-statistic values compared to the BODE and ADO indices ( 0.701 vs 0.677 vs 0.644 , respectively). The prognostic power was more definitive when applied to the Dutch validation (CIROCO+) cohort ( 0.842 vs 0.799 vs 0.825 , respectively).

Conclusions. The CADOT index has comparable prognostic power to the BODE and ADO indices. The CADOT is complementary/an alternative to the BODE (if 6-MWT is not feasible) and ADO (with less dependence on the age factor) indices. Trial registration: ClinicalTrials.gov (NCT01923051).

Key words: COPD, prognostic index, pulmonary function, mortality

Received: April 3, 2020; Revised: July 10, 2020; Accepted: August 10, 2020; Available online: September 10, 2020

https://doi.org/10.5507/bp.2020.035

(c) 2021 The Authors; https://creativecommons.org/licenses/by/4.0/

${ }^{a}$ Department of Respiratory Diseases, University Hospital Brno, Brno, Czech Republic

bInstitute of Biostatistics and Analyses, Ltd., Brno, Czech Republic

'Faculty of Medicine, Masaryk University, Brno, Czech Republic

${ }^{d}$ Department of Respiratory Medicine, University Hospital Olomouc, Czech Republic

ePulmonary Department, University Hospital Ostrava, Czech Republic

${ }^{f}$ Pulmonary Department, Bulovka Hospital, Prague, Czech Republic

${ }^{9}$ Boehringer Ingelheim s.r.o., Prague, Czech Republic

${ }^{h}$ Department of Research and Education, CIRO, Center of Expertise for Chronic Organ Failure, Horn, The Netherlands

${ }^{i}$ COPD Center, Sahlgrenska University Hospital, Institute of Medicine, University of Gothenburg, Sweden

${ }^{i}$ REVAL Rehabilitation Research Center, BIOMED Biomedical Research Institute, Faculty of Rehabilitation Sciences, Hasselt University, Diepenbeek, Belgium

${ }^{k}$ Department of Respiratory Medicine, Maastricht University Medical Centre, NUTRIM School of Nutrition and Translational Research in Metabolism, Maastricht, The Netherlands

'Pulmonary Department, University Hospital Hradec Kralove and Faculty of Medicine Hradec Kralove, Charles University, Czech Republic "These authors contributed equally to this work

Corresponding author: Kristian Brat, e-mail: kristian.brat@seznam.cz

\section{INTRODUCTION}

According to the latest World Health Organization data, chronic obstructive pulmonary disease (COPD) was the third leading cause of death worldwide, claiming approximately 3 million lives in 2016 (ref. ${ }^{1}$ ). In the Czech Republic, the annual COPD-related death rate is around 3,500 events per 10.6 million population ${ }^{2}$. According to an epidemiological prediction model, COPD prevalence is expected to rise in the coming years ${ }^{3}$.
COPD is considered a heterogeneous syndrome with inter-individual differences in disease manifestation, comorbidity and long-term mortality risk ${ }^{4,5}$. For this reason, accurate tools for estimating the life expectancy of COPD patients are warranted ${ }^{6,7}$. The BODE (Body mass index, airflow Obstruction, Dyspnoea and Exercise) and the ADO (Age, Dyspnoea and Obstruction) indices are globally the most widely used instruments for long-term mortality assessment ${ }^{8,9}$. A number of other prediction tools have been constructed, e.g. the e-BODE, BODEx and 
COTE (ref. ${ }^{10,11}$ ). Use of the BODE (and derived indices) may be difficult in some patients (e.g. with a disability) or in some outpatient settings where the 6-minute walk test (6-MWT) cannot be performed (e.g. lack of a 30-meter corridor). Two of the 3 parameters determining the ADO score may be associated with other confounders the specificity of the mMRC score (alternative causes of dyspnoea - pulmonary "other-than-COPD”, cardiogenic, extrathoracic, neuromuscular, systemic, etc.) and the age factor (mortality risk/rate is strongly determined by age - the "Gompertz-Makeham Law of Mortality") (ref.9,12,13).

The Czech Multicenter Research Database of COPD (CMRD) comprises a large number of regularly monitored COPD patients ${ }^{14}$. Based on an analysis of all-cause mortality in CMRD COPD subjects, the aim of the present research was to construct an alternative long-term prognostic instrument for use in situations where the BODE score cannot be calculated and that would improve the ADO index by augmenting the role of COPD-specific conditions predictive of poorer prognosis.

\section{METHODS}

\section{The derivation cohort (Czech Republic)}

The data for development of the new scale were extracted from the CMRD Registry ${ }^{14}$, an observational prospective study with a primary objective to monitor and assess morbidity and all-cause mortality in patients with moderate to very severe COPD (Global Initiative for Obstructive Lung Disease (GOLD) grades II to IV) in the Czech Republic (ClinicalTrials.gov Identifier: NCT01923051). Patients were recruited in 14 centers providing specialised respiratory care between February 2013 and December 2016. Follow-up of patients within the CMRD Registry is still ongoing. Detailed description was published elsewhere ${ }^{14}$.

At the time of the new prognostic instrument construction (July 2016), the registry included 699 COPD patients. Parameters assessed at enrolment included demographics, patient history data [general practitioners' (GPs') and specialists' records], symptoms [dyspnoea - mMRC score $^{15}$, COPD Assessment Test (CAT) (ref. ${ }^{16}$ )], quality of life measures [St George's Respiratory Questionnaire (SGRQ) (ref. $\left.{ }^{17}\right)$ ], treatment, pulmonary functions and other clinical examinations (chest CT, ECG, blood gases, echocardiography etc.). GPs' and specialists' records were also used to identify chronic heart failure (CHF).

\section{The validation cohort (Netherlands)}

To validate the new prognostic index, data from the CIROCO+ cohort, an observational single-center study, were used $^{18}$. Patients with moderate to very severe COPD (GOLD grades II to IV) (ref. ${ }^{19}$ ), aged 40 to 80 years and in a clinically stable condition were prospectively recruited between November 2007 and November 2010 during initial evaluation of a comprehensive pulmonary rehabilitation program at $\mathrm{CIRO}+\left(\right.$ ref. $\left.^{20}\right)$. CHF was identified from patient history (Charlson comorbidity index); $\mathrm{FEV}$, and $\mathrm{TL}_{\mathrm{CO}}$ values were measured at inclusion ${ }^{20}$.

\section{Development of the new index}

The steps to develop the new index included identification of parameters discriminating between patients who died and those who were alive (Step 1), testing of the discriminatory power of these parameters (Step 2) and refinement with a reclassification analysis (Step 3).

The derivation cohort was separated into patients who died and those who were alive at the time of analysis. Clinical characteristics of these two subgroups were compared using the Mann-Whitney U-test and the Fisher exact test to identify parameters discriminating between the two subgroups (Step 1).

The discriminatory power of the identified parameters (Step 2) was tested with the receiver operating characteristic (ROC) analysis. The ROC analysis included the existing ADO and BODE indices alone and ADO and BODE indices with addition of the risk parameters identified during Step 1. The quality of fit was assessed with the c-statistic that equals the area under the ROC curve. The significance of the differences between the ROC curves was tested with the DeLong test ${ }^{21}$.

Reclassification analyses (Step 3), namely the NRI and IDI methods ${ }^{22,23}$, were used for parameters that significantly increased the c-statistics (the ROC analysis) of the ADO/BODE to further refine selection of components for the new prognostic index; only the parameters with significant results in the reclassification analysis were included in the final index.

Logistic regression was used to calculate the risk of death for the newly added parameters and, based on this, patients were divided into risk groups. Each group was assigned risk points that these parameters added to the new scale. The risk points were determined by rounding the ORs from the logistic regression. The new index was then divided into risk categories with similar prognostic power.

To validate the new scale, we calculated long-term survival estimates for the derivation (July 2016) and validation (April 2017) cohorts to assess differences in mortality risk between subgroups assigned to the risk categories. The CMRD Registry is still an ongoing project and the prospective nature of the study enabled us to reassess the prognostic utility of the CADOT twice more in March 2018 and in January 2020, in order to confirm its unique prognostic properties.

All presented analyses were performed using the IBM SPSS Statistics 24.0 (ref. ${ }^{24}$ ) and R-studio software (ref. ${ }^{25}$ ). All statistical tests used $\alpha=0.05$ as the level of significance.

\section{RESULTS}

Step 1: The derivation cohort (median follow-up 18.5 months) was split into subgroups of 616 alive and 83 dead patients. The two subgroups differed in the total ADO and BODE scores as well as the individual parameters within the two indices. Concurrently, we observed lower values of pulmonary function tests $\left(\mathrm{FEV}_{1} / \mathrm{FVC}, \mathrm{TL}_{\mathrm{CO}}, \mathrm{K}_{\mathrm{CO}}\right)$ in the subgroup of dead vs living patients $(P<0.001$ for all). CHF was significantly more frequent in the dead vs alive subgroup (33.7\% vs $15.0 \%$ ). Detailed characteristics of 
Table 1. Descriptive statistics of the derivation (CZ) cohort ( $n=699)$.

\begin{tabular}{|c|c|c|c|c|}
\hline & \multirow{2}{*}{ Total } & \multicolumn{2}{|c|}{ Death } & \multirow{2}{*}{$P$} \\
\hline & & No & Yes & \\
\hline Sex - men (n, \%) & $517(74.0 \%)$ & $454(73.7 \%)$ & $63(75.9 \%)$ & 0.790 \\
\hline $\begin{array}{l}\text { Age at inclusion } \\
\text { (median, } 5^{\text {th }} ; 95^{\text {th }} \text { percentile) }\end{array}$ & $67.0(51.4 ; 81.1)$ & $66.7(50.2 ; 79.8)$ & $68.9(60.9 ; 85.0)$ & $<0.001$ \\
\hline $\begin{array}{l}\text { Age at diagnosis } \\
\text { (median, } 5^{\text {th. }} 995^{\text {th }} \text { percentile) }\end{array}$ & $58.9(38.7 ; 74.4)$ & $58.4(37.7 ; 73.2)$ & $63.9(50.5 ; 80.7)$ & $<0.001$ \\
\hline $\begin{array}{l}\text { BMI } \\
\text { (median, } 5^{\text {th }} ; 95^{\text {th }} \text { percentile) }\end{array}$ & $26.8(18.6 ; 38.0)$ & $27.2(18.8 ; 38.1)$ & $23.9(17.5 ; 37.0)$ & $<0.001$ \\
\hline Atopy $(\mathrm{n}, \%)$ & $90(12.9 \%)$ & $77(12.5 \%)$ & $13(15.7 \%)$ & 0.388 \\
\hline Asthma (n, \%) & $71(10.2 \%)$ & $66(10.7 \%)$ & $5(6.0 \%)$ & 0.245 \\
\hline Heart failure (n, \%) & $120(17.2 \%)$ & $92(15.0 \%)$ & $28(33.7 \%)$ & $<0.001$ \\
\hline Atrial fibrillation (n, \%) & $89(12.8 \%)$ & $73(11.9 \%)$ & $16(19.3 \%)$ & 0.078 \\
\hline Diabetes mellitus (n, \%) & $162(23.2 \%)$ & $143(23.3 \%)$ & $19(22.9 \%)$ & 0.999 \\
\hline Depression (n, \%) & $136(19.5 \%)$ & $109(17.7 \%)$ & $27(32.5 \%)$ & 0.003 \\
\hline Apnoea (n, \%) & $51(7.3 \%)$ & $47(7.6 \%)$ & $4(4.8 \%)$ & 0.500 \\
\hline $\mathrm{FEV}_{1}(\%)\left(\right.$ median, $5^{\text {th }} ; 95^{\text {th }}$ percentile $)$ & $45.6(25.1 ; 60.4)$ & $46.7(25.2 ; 60.6)$ & $39.5(18.5 ; 58.6)$ & $<0.001$ \\
\hline FVC (\%) (median, $5^{\text {th }} ; 95^{\text {th }}$ percentile $)$ & $67.7(39.7 ; 99.0)$ & $68.5(41.6 ; 99.0)$ & $62.6(33.2 ; 93.3)$ & 0.057 \\
\hline $\mathrm{FEV}_{1} / \mathrm{FVC}$ (median, $5^{\text {th }} ; 95^{\text {th }}$ percentile) & $0.53(0.33 ; 0.73)$ & $0.53(0.34 ; 0.72)$ & $0.48(0.31 ; 0.73)$ & 0.014 \\
\hline $\mathrm{TL}_{\mathrm{CO}}(\%)\left(\right.$ median, $5^{\text {th }} ; 95^{\text {th }}$ percentile $)$ & $50.0(22.0 ; 96.0)$ & $52.0(22.0 ; 97.0)$ & $37.0(18.0 ; 61.0)$ & $<0.001$ \\
\hline $\mathrm{K}_{\mathrm{CO}}(\%)\left(\right.$ median, $5^{\text {th }} ; 95^{\text {th }}$ percentile $)$ & $67.0(31.0 ; 115.0)$ & $68.0(32.0 ; 116.0)$ & $55.0(24.0 ; 93.0)$ & $<0.001$ \\
\hline 6-MWD $(\mathrm{m})\left(\right.$ median, $5^{\text {th }} ; 95^{\text {th }}$ percentile $)$ & $350.5(110.0 ; 528.0)$ & $360.0(120.0 ; 530.0)$ & $243.0(60.0 ; 460.0)$ & $<0.001$ \\
\hline BODE index (median, $5^{\text {th }} ; 95^{\text {th }}$ percentile, & $4.0(1.0 ; 8.0)$ & $4.0(1.0 ; 8.0)$ & $5.0(2.0 ; 9.0)$ & $<0.001$ \\
\hline mean, SD) & $4.2(2.1)$ & $4.0(2.1)$ & $5.3(2.0)$ & \\
\hline ADO index (median, $5^{\text {th }} ; 95^{\text {th }}$ percentile, & $5.0(2.0 ; 7.0)$ & $5.0(2.0 ; 7.0)$ & $5.0(3.0 ; 8.0)$ & $<0.001$ \\
\hline mean, SD) & $4.8(1.6)$ & $4.6(1.5)$ & $5.5(1.6)$ & \\
\hline
\end{tabular}

6-MWD = Six Minute Walking Distance; ADO = Age, Dyspnoea and airflow Obstruction; BMI = Body Mass Index; BODE = Body-mass index, airflow Obstruction, Dyspnoea, and Exercise; $\mathrm{FEV}_{1}=$ Forced Expiratory Volume in 1 Second; FVC $=$ Forced Vital Capacity; $\mathrm{K}_{\mathrm{CO}}=\mathrm{Transfer}$ Coefficient for Carbon Monoxide; $\mathrm{TL}_{\mathrm{CO}}=$ diffusing capacity (Transfer Factor) for Carbon Monoxide

Table 2. Assignment of points for the CADOT index.

\begin{tabular}{lcccccc}
\hline & 0 points & 1 point & 2 points & 3 points & 4 points & 5 points \\
\hline CHF & No & & & Yes & & $\geq 90$ \\
Age & $40-49$ & $50-59$ & $60-69$ & $70-79$ & $80-89$ & - \\
mMRC & $0-1$ & 2 & 3 & 4 & - & - \\
FEV $_{1}$ & $\geq 65$ & $64-36$ & $\leq 35$ & - & - & - \\
$\mathrm{TL}_{\mathrm{CO}}$ & $\geq 45$ & $30-44$ & $<30$ & - \\
\hline
\end{tabular}

$\mathrm{CHF}=$ Chronic Heart Failure; FEV $_{1}=$ Forced Expiratory Volume in 1 Second; mMRC = modified Medical Research Council dyspnoea scale; $\mathrm{TL}_{\mathrm{CO}}=$ diffusing capacity (Transfer Factor) for Carbon Monoxide

the derivation cohort and its subgroups are presented in Table 1.

Step 2: Since total ADO/BODE and their individual items discriminated between the two subgroups, the ADO and BODE indices were used as platforms for the development of a new index.

The potential of the newly identified parameters, i.e. $\mathrm{CHF}, \mathrm{FEV}_{1} / \mathrm{FVC}, \mathrm{TL}_{\mathrm{CO}}$ and $\mathrm{K}_{\mathrm{CO}}$ to increase the discriminative power for all-cause mortality prediction of the existing risk indices (ADO/BODE) is presented in the Table
A1. The DeLong test showed that adding $\mathrm{CHF}, \mathrm{TL}_{\mathrm{CO}}$ and $\mathrm{K}_{\mathrm{CO}}$ to the ADO platform provided statistically significant differences in mortality prediction. No significant result was identified for any combination of the new parameters and the BODE.

Consequently, $\mathrm{CHF}, \mathrm{TL}_{\mathrm{CO}}$ and $\mathrm{K}_{\mathrm{CO}}$ were entered in the reclassification analysis (Step 3) using the ADO platform as the cornerstone. The reclassification analysis showed $\mathrm{CHF}$ and $\mathrm{TL}_{\mathrm{CO}}$ to be appropriate for definitive use as additional factors for mortality prediction (Table A2). 
Table 3. Prediction of 2-year mortality ( $95 \%$ CI) according to the CADOT total score.

\begin{tabular}{llll}
\hline Category & Score & Derivation cohort & Validation cohort \\
\hline CADOT 1 & $0-2$ & $0.0 \%$ & $0.0 \%$ \\
CADOT 2 & $3-5$ & $7.9 \%(3.2 \%-12.5 \%)$ & $4.3 \%(0.2 \%-8.5 \%)$ \\
CADOT 3 & $6-9$ & $15.2 \%(9.0 \%-21.5 \%)$ & $20.5 \%(6.9 \%-34.1 \%)$ \\
CADOT 4 & $10-15$ & $45.4 \%(21.0 \%-69.9 \%)$ & - \\
\hline
\end{tabular}

$\mathrm{CADOT}=$ Chronic heart failure, Age, Dyspnoea, airflow Obstruction, $\mathrm{TL}_{\mathrm{CO}}$ - diffusion capacity (Transfer factor) for Carbon Monoxide; $\mathrm{CI}=$ Confidence Interval

Therefore, the development process resulted in a new prognostic index with 5 components, i.e. CHF, Age, Dyspnoea (mMRC score), Obstruction ( $\mathrm{FEV}_{1}$ - \% of predicted value) and $\mathrm{TL}_{\mathrm{CO}}$ (\% of predicted value) (CADOT). CHF was assigned 0 points (absent) and 3 points (present; rounded $\mathrm{OR}=3$ ). $\mathrm{TL}_{\mathrm{CO}}$ values were categorized into three categories and assigned 0 points $(\geq 45 \%), 1$ point $(30-44 \%)$ and 2 points $(<30 \%)$. The rating of the individual items of the CADOT index is described in Table 2. The CADOT scores can range between 0 and 15 points. Detailed characteristics of the CMRD cohort with complete CADOT data are presented in Table A3. Like the BODE index, the individual scores were split into 4 prognostic categories (low risk, intermediate risk, high risk, very high risk of death) with similar prognostic power (Table A3 and Table 3).

\section{Validation}

Characteristics of the validation cohort (median follow-up 26.2 months) are presented in Table A4. The outcomes of the validation are presented in Table 3 (the CADOT index performance), Table 4 (prognostic power of the BODE, ADO and CADOT) and in Fig. 1 (longterm survival estimates).

Estimated two-year survival rates for the low, intermediate, high and very high risk groups were $100 \%, 92.1 \%$, $84.8 \%$ and $54.6 \%$, respectively $(P<0.001)$ in the derivation cohort, $100 \%, 95.7 \%, 79.5 \%$ and N/A, respectively $(P<0.001)$ in the validation cohort.

\section{Confirmation of prognostic utility of the CADOT from a long-term perspective}

The c-statistic of the CADOT in the March 2018 reassessment was $0.685(P<0.001)$. In the last reassessment in January 2020, estimated five-year survival rates for the low, intermediate, high and very high risk groups were $88.9 \%, 66.7 \%, 42.6 \%$ and $22.9 \%$, respectively $(P<0.001)$. (Fig. A1).

\section{DISCUSSION}

The BODE index is the most widely used and globally accepted instrument for COPD prognosis assessment. We present a complementary/ alternative prognostic tool, the CADOT index. Having comparable prognostic power to the BODE and ADO indices, the CADOT has features that may be of special benefit in selected settings, in par-
Table 4. ROC analysis - index capacity to separate patients according to mortality.

\begin{tabular}{lllc}
\hline Index & Cohort & C-statistics $(95 \% \mathrm{CI})$ & $P$ \\
\hline BODE & Derivation cohort & $0.677(0.610-0.744)$ & $<\mathbf{0 . 0 0 1}$ \\
& Validation cohort - NL & $0.799(0.681-0.917)$ & $<\mathbf{0 . 0 0 1}$ \\
\hline ADO & Derivation cohort & $0.644(0.581-0.706)$ & $<\mathbf{0 . 0 0 1}$ \\
& Validation cohort - NL & $0.825(0.735-0.914)$ & $<\mathbf{0 . 0 0 1}$ \\
\hline CADOT & Derivation cohort & $0.701(0.625-0.776)$ & $<\mathbf{0 . 0 0 1}$ \\
& Validation cohort - NL & $0.842(0.755-0.930)$ & $<0.001$ \\
\hline
\end{tabular}

$\mathrm{ADO}=$ Age, Dyspnoea and airflow Obstruction; BODE $=$ Bodymass index, airflow Obstruction, Dyspnoea, and Exercise; CADOT = Chronic heart failure, Age, Dyspnoea, airflow Obstruction, $\mathrm{TL}_{\mathrm{CO}}-$ diffusion capacity (Transfer factor) for Carbon Monoxide

ticular, if the 6-MWT is not practicable. The CADOT index also functioned well in subjects with milder airway obstruction (Table 4) and its properties were confirmed on an independent validation cohort.

The CADOT addresses some specific weaknesses of the ADO and BODE, such as 6-MWT in BODE or the impact of age on ADO.

Disabled or unfit COPD patients (e.g. severe arthrosis, polyneuropathy, lower limb amputees) may be unable (or unwilling) to undergo the 6-MWT or complete a shorter distance and fall into a BODE poorer prognosis. In addition, not all medical offices are equipped to perform the 6-MWT (e.g. lack of a 30-meter corridor). Consequently, the BODE may be of limited use in COPD populations with disability/immobility. In 2009, Puhan et al. attempted to increase the prognostic accuracy of the BODE and ADO indices'. For BODE ("updated BODE index"), the main difference was the 6-MWT scoring where the different walking distances were assigned $0(>350 \mathrm{~m}), 4$ (250$349 \mathrm{~m}), 7(150-249 \mathrm{~m})$ or 9 points $(<150 \mathrm{~m})$, respectively9. However, this modification reinforced the reliance of the BODE on the 6-MWT, since a single one meter difference in walking distance (e.g. 350 vs $349 \mathrm{~m}$ ) may result in a total score change of up to 4 points $^{9}$. Since the CADOT does not include the 6-MWT, the issues associated with the 6-MWT are completely avoided.

The ADO index is based on age, $\mathrm{FEV}_{1}$ and $\mathrm{mMRC}$ score assessments 9 . Up to $50 \%$ of the total score is determined by age alone ( 5 points of the 10-point scale assigned to age $>90$ years) $\left(\right.$ ref. $\left.^{9}\right)$. The 2012 ADO update 


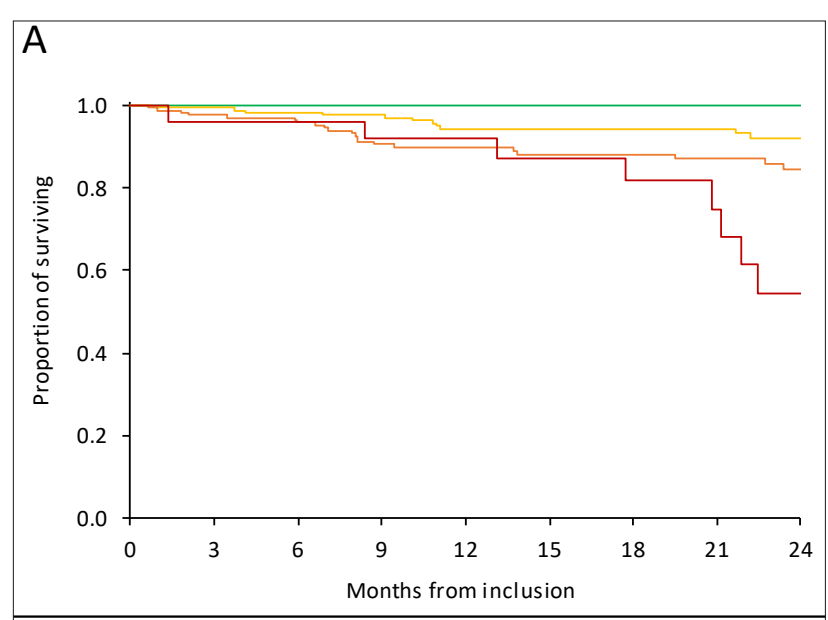

B

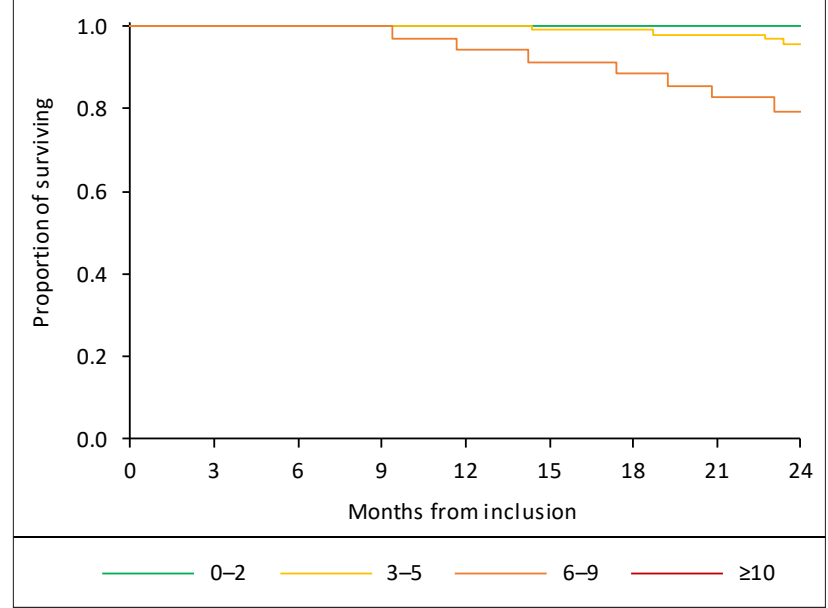

Fig. 1. Long-term survival according to the CADOT index (comparison of the derivation - CZ (A) and validation - NL (B) cohorts). CZ - Czech Republic; NL - Netherlands

maintains the prominence of the age factor (up to 7 of 14 points assigned for age $>80$ years) $\left(\right.$ ref $\left.^{26}\right)$.

Addition of $\mathrm{CHF}$ and $\mathrm{TL}_{\mathrm{CO}}$ to the $\mathrm{ADO}$ index enabled us to develop a prognostic tool based on a well-established platform but reducing its dependence on age.

Evidence shows that $\mathrm{CHF}$ is a frequent comorbidity and one of the most important causes of death among COPD patients ${ }^{27-29}$. Our derivation cohort included $17.2 \%$ of patients with concurrent $\mathrm{CHF}$ and this comorbidity was shown to be one of the main drivers of mortality in our cohort. CHF was also frequent in other cohorts, e.g. in the POPE study, the prevalence of CHF ranged between $10.8 \%$ and $19.4 \%$ according to disease phenotype; for the frequent-exacerbator phenotypes (with obviously higher mortality risk) it was $16.6 \%$ and $19.4 \%$, respectively ${ }^{30}$.

In COPD patients, reduced $\mathrm{TL}_{\mathrm{CO}}$ usually reflects the presence of emphysema, pulmonary arterial hypertension or CHF that are all associated with increased risk of longterm mortality ${ }^{27,31,32}$. In Central Europe, COPD patients are cared for mainly by pulmonary physicians, unlike Western Europe, where GPs are the prevailing caregiv- $\mathrm{ers}^{33}$. In the Czech Republic, around $80 \%$ of outpatient non-hospital respiratory practices are equipped with (or have access to) a diffusion capacity assessment device. The situation is similar in Germany (personal communication with the Lemon Medical GmBH). Recent analysis of the POPE cohort illustrated that TLco vs 6-MWT data were available in $90 \%$ vs $11 \%$ of Croatians and $63 \%$ vs $20 \%$ of Czechs with COPD (ref. ${ }^{30,34}$ ). This means that in some regions or countries, TLco assessment may be more accessible than a $\sim 30$-meter corridor, i.e. the 6-MWT.

The CADOT index performed equally well in various populations of patients (CMRD and CIROCO). CMRD represents a population of moderate-to-very severe COPD subjects with higher (> 17\%) prevalence of CHF, while the CIROCO cohort included more patients with milder airway obstruction (mean $\mathrm{FEV}_{1}$ was $50 \%$ ). In addition, the CIROCO patients were younger, had higher mean $\mathrm{TL}_{\mathrm{CO}}(56 \%)$ and $\mathrm{CHF}$ was less prevalent (3\%). This was consequent to the CIROCO study exclusion criteria (unstable COPD, myocardial infarction in the previous 6 months, asthma history, alpha-1 antitrypsine deficiency, previous lung surgery, malignancy in the previous 5 years) $\left(\right.$ ref. $\left.{ }^{18}\right)$. Importantly, the prognostic power (c-value) of the CADOT was higher in the "milder" COPD population of the CIROCO cohort. Since the long-term mortality risk among GOLD I subjects is very low, a large cohort of these subjects and a year-long follow-up would be needed to learn the prognostic properties of CADOT in this category of patients. An easy way for assessing risk among GOLD I patients using CADOT is a periodical (e.g., annual) calculation of the CADOT score where the disease progression/deterioration can be captured.

Our study has limitations. First, the derivation cohort included patients from tertiary and university hospitalbased centers and thus, further external validation on larger cohorts with higher proportions of mild COPD patients are desirable. Second, the $\mathrm{TL}_{\mathrm{CO}}$ test may be less available in primary care settings. However, this is strongly region/ country-dependent and the availability of $\mathrm{TL}_{\mathrm{CO}}$ in some regions or countries may exceed that of 6-MWT. For example, in Czechia, the availability of $\mathrm{TL}_{\mathrm{CO}}$ for respiratory physicians is more than $80 \%$. Third, the presence of CHF has not been re-assessed at patient inclusion. However, of the 120 CMRD subjects with a history of CHF, 29 had an echocardiographic (ECHO) examination of the heart within the CMRD study protocol (ECHO was a non-mandatory test). Of these, 26 patients (93\%) had ECHO signs compatible with left- or right-sided CHF. Of the remaining 94 subjects with a CHF history, 87 (93\%) were treated with 1 or more CHF treatments (ACE inhibitors, angiotensin II receptor antagonists, betablockers, diuretics). These data suggest reliability of the patient history data from the CMRD database. Fourth, our cohorts included a lower portion of patients with COPD, GOLD grade I. Though the CADOT performed well on a cohort with milder airway obstruction, further studies are needed to assess the utility of the CADOT in GOLD grade I subjects. Finally, the majority of both cohorts was composed of men $(74 \%$ of the derivation cohort and $58 \%$ of the validation cohort, respectively) and the applicability to 
women may be somewhat limited. However, in the the BODE and ADO construction studies, the proportion of men and women was unequal as well - in the 2012 study of Puhan et al, the proportion of men was $60 \%$, while in the Puhan study of 2009, men accounted for a $60 \%$ (Swiss cohort) and 93\% (Spanish cohort) (ref.9,12).

\section{CONCLUSIONS AND IMPLICATIONS}

We constructed and validated a new prognostic index (CADOT) that has slightly higher prognostic power than the BODE and ADO indices. The CADOT is complementary (or alternative) to the BODE in situations where 6-MWT is not feasible. The CADOT index improves the ability of respiratory physicians to determine risk for patients with COPD and severe comorbidities.

Acknowledgements: The authors would like to thank to physicians and their nursing staff (not mentioned as authors) of all participating centers of the CMRD of COPD, for assistance with data collection, namely: Petra Vogelova, Tomas Dvorak - Pulmonary Department, Hospital Mlada Boleslav, Petr Safranek - Pulmonary Department, University Hospital, Pilsen, Ondrej Sobotik - Pulmonary Department, University Hospital Motol, Prague, Rostislav Simek - Pulmonary Department, Regional Hospital of T. Bata, Zlin, Jaroslav Lnenicka, Blanka Snelerova Pulmonary Department, Masaryk Hospital, Usti nad Labem, Zuzana Liptakova - Pulmonary Department, Ceske Budejovice Hospital, Libor Nevoranek, Eva Kocova, Michal Kopecky, Sarka Pracharova, and Lukas Varhanik - University Hospital Hradec Kralove, Lucie Heribanova - Pulmonary Department, Thomayer Hospital, Prague, Katerina Neumannova - Palacky University, Olomouc and Milada Sipkova - Pulmonary Department, Liberec Hospital.

Author contributions: All authors contributed to the data collection, analysis and interpretation and writing of the manuscript. MS, $\mathrm{KH}, \mathrm{KB}, \mathrm{VK}$ : had full access to all CMRD data in the study and take the responsibility for the integrity of the data and the accuracy of the data analysis; MS: carried out the statistical analysis; VK, KH: conceived and designed the CMRD study in the 2012; $\mathrm{BN}$ : took the responsibility for CMRD project registration at ClinicalTrials.gov (NCT01923051) and for validation of CMRD data; KB, MP, MS, DE, VK: drafted the manuscript; DE: edited the English language; VK: obtained funding. All authors critically revised the manuscript for important intellectual content and approved the submitted version. All authors are committed to ensuring that questions related to the accuracy and integrity of any part of the work are appropriately investigated and resolved.

Conflict of interest statement: The authors declare there are no conflicts of interest related to the manuscript content.

Role of sponsors: CMRD research project has been funded by Ministry of Health of the Czech Republic (15/14/ NAP, 5/15/NAP, UHHK 00179906, MH CZ-DRO FNBr 65269705), and the Charles University Czech Republic
(PROGRES Q40, and PROGRES Q42), and a consortium of several pharmaceutical companies (Angelini, AstraZeneca, Boehringer Ingelheim, Cipla, CSL Behring, GSK, Novartis, and Sandoz). All companies supported the CMRD project via unrestricted research grants. The sponsors had no role in the design of the study, the collection and analysis of the data, or the preparation of the manuscript. The opinions, results, and conclusions reported in this article are independent of the funding sources.

Author statement: Both research protocols (CMRD, CIROCO+) were approved by the relevant ethics committees, and written consent was obtained from all participants.

\section{REFERENCES}

1. The top ten causes of death. http://www.who.int/news-room/factsheets/detail/the-top-10-causes-of-death. [Accessed: 23 March, 2020

2. Koblížek V, Svoboda M. Current position of new fixed-dose combination of tiotropium and olodaterol - its role in the treatment of chronic obstructive pulmonary disease in the Czech Republic. Vnitr Lek 2016;62(12):1011-20. (In Czech)

3. Burgel PR, Laurendeau C, Raherison C, Fuhrman C, Roche N. An attempt at modeling COPD epidemiological trends in France. Respir Res 2018;19(1):130.

4. Burney PG, Patel J, Newson R, Minelli C, Naghavi M. Global and regional trends in COPD mortality, 1990-2010. Eur Respir J 2015;45(5):1239-47.

5. Golpe R, Suárez-Valor M, Martín-Robles I, Sanjuán-López P, CanoJiménez C, Castro-Añón O, Pérez de Llano LA. Mortality in COPD patients according to clinical phenotypes. Int J Chron Obstruct Pulmon Dis 2018;13:1433-9.

6. Kinney GL, Santorico SA, Young KA, Cho MH, Castaldi PJ, San José Estépar R, Ross JC, Dy JG, Make BJ, Regan EA, Lynch DA, Everett DC, Lutz SM, Silverman EK, Washko GR, Crapo JD, Hokanson JE; COPDGene Investigators. Identification of Chronic Obstructive Pulmonary Disease Axes That Predict All-Cause Mortality: The COPDGene Study. Am J Epidemiol 2018;187(10):2109-16.

7. Brat K, Plutinsky M, Hejduk K, Svoboda M, Popelkova P, Zatloukal J, Volakova E, Fecaninova M, Heribanova L, Koblizek V. Respiratory parameters predict poor outcome in COPD patients, category GOLD 2017 B. Int J Chron Obstruct Pulmon Dis 2018;13:1037-52.

8. Celli BR, Cote CG, Marin JM, Casanova C, Montes de Oca M, Mendez R, Pinto Plata V, Cabral HJ. The body-mass index, airflow obstruction, dyspnea, and exercise capacity index in chronic obstructive pulmonary disease. N Engl J Med 2004;350(10):1005-12.

9. Puhan MA, Garcia-Aymerich J, Frey M, ter Riet G, Antó JM, Agustí A, Gómez FP, Rodríguez-Roisín R, Moons KG, Kessels AG, Held U. Expansion of the prognostic assessment of patients with chronic obstructive pulmonary disease: the updated BODE index and the ADO index. Lancet 2009;374(9691):704-71.

10. Soler-Cataluña JJ, Martínez-García MA, Sánchez LS, Tordera MP, Sánchez PR. Severe exacerbations and BODE index: two independent risk factors for death in male COPD patients. Respir Med 2009;103(5):692-9.

11. Azarisman MS, Fauzi MA, Faizal MP, Azami Z, Roslina AM, Roslan $H$. The SAFE (SGRQ score, air-flow limitation and exercise tolerance) Index: a new composite score for the stratification of severity in chronic obstructive pulmonary disease. Postgrad Med J 2007;83(981):492-7.

12. Puhan MA, Hansel NN, Sobradillo $P$, Enright $P$, Lange $P$, Hickson $D$, Menezes P, ter Riet G, Held U, Domingo-Salvany A, Mosenifar Z, Antó JM, Moons KG, Kessels AG, Garcia-Aymerich J; International COPD Cohorts Collaboration Working Group. Large-scale international validation of the ADO index in subjects with COPD: an individual subject data analysis of 10 cohorts. BMJ Open 2012;2(6):e002152.

13. Milevsky M. (2015). The Gompertz-Makeham Law of Mortality. In King William's Tontine: Why the Retirement Annuity of the Future 
Should Resemble its Past (pp. 226-229). Cambridge: Cambridge University Press. doi:10.1017/CBO9781139879316.012.

14. Novotna B, Koblizek V, Zatloukal J, Plutinsky M, Hejduk K, Zbozinkova Z, Jarkovsky J, Sobotik O, Dvorak T, Safranek P. Czech multicenter research database of severe COPD. Int J Chron Obstruct Pulmon Dis 2014;9:1265-74.

15. Mahler DA, Wells CK. Evaluation of Clinical Methods for Rating Dyspnea. Chest 1988;93(3):580-6.

16. Jones PW, Harding G, Berry P, Wiklund I, Chen WH, Kline Leidy N. Development and first validation of the COPD Assessment Test. Eur Respir J 2009;34(3):648-54.

17. Jones PW, Quirk FH, Baveystock CM. The St George's Respiratory Questionnaire. Respir Med 1991;85 Suppl B:25-31.

18. Vanfleteren LE, Spruit MA, Groenen M, Gaffron S, van Empel VP, Bruijnzeel P, Rutten EP, Op't Roodt J, Wouters EF, Franssen FM. Clusters of comorbidities based on validated objective measurements and systemic inflammation in patients with chronic obstructive pulmonary disease. Am J Respir Crit Care Med 2013;187(7):728-35.

19. Vestbo J, Hurd SS, Agustí AG, Jones PW, Vogelmeier C, Anzueto A Barnes PJ, Fabbri LM, Martinez FJ, Nishimura M, Stockley RA, Sin DD, Rodriguez-Roisin R. Global Strategy for the Diagnosis, Management and Prevention of Chronic Obstructive Pulmonary Disease, GOLD Executive Summary. Am J Respir Crit Care Med 2013;187(4):347-65.

20. Spruit MA, Vanderhoven-Augustin I, Janssen PP, Wouters $\mathrm{EF}$. Integration of pulmonary rehabilitation in COPD. Lancet 2008;371(9606):12-13.

21. DeLong ER, DeLong DM, Clarke-Pearson DL. Comparing the areas under two or more correlated receiver operating characteristic curves: a nonparametric approach. Biometrics 1988:44(3):837-45

22. Pencina MJ, D'Agostino RB, Steyerberg EW. Extensions of net reclassification improvement calculations to measure usefulness of new biomarkers. Stat Med 2011;30(1):11-21.

23. Pencina MJ, D'Agostino RB, D'Agostino RB Jr, Vasan RS. Evaluating the added predictive ability of a new marker: From area under the ROC curve to reclassification and beyond. Stat Med 2008;27(2):157-72.

24. IBM Corp. Released 2016. IBM SPSS Statistics for Windows, Version 24.0. Armonk, NY: IBM Corp. https://www.ibm.com/support/pages/ how-cite-ibm-spss-statistics-or-earlier-versions-spss. [Accessed: 23 March, 2020]

25. RStudio Team (2015). RStudio: Integrated Development for R RStudio, Inc., Boston. https://support.rstudio.com/hc/en-us/ articles/206212048-Citing-RStudio. Accessed on March 23rd, 2020.
26. Sferrazza Papa GF, Battaglia S, Solidoro P. Novelties in COPD prognosis: evolution of survival indexes. Minerva Med 2015;106(2 Suppl 2):9-16.

27. Sin DD, Anthonisen NR, Soriano JB, Agusti AG. Mortality in COPD: Role of comorbidities. Eur Respir J 2006;28(6):1245-57.

28. Slenter RH, Sprooten RT, Kotz D, Wesseling G, Wouters EF, Rohde GG. Predictors of 1-year mortality at hospital admission for acute exacerbations of chronic obstructive pulmonary disease. Respiration 2013;85(1):15-26

29. Steer J, Gibson GJ, Bourke SC. Predicting outcomes following hospitalization for acute exacerbations of COPD. QJM 2010;103(11):81729.

30. Koblizek V, Milenkovic B, Barczyk A, Tkacova R, Somfay A, Zykov K, Tudoric N, Kostov K, Zbozinkova Z, Svancara J, Sorli J, Krams A, Miravitlles M, Valipour A. Phenotypes of COPD patients with a smoking history in Central and Eastern Europe: the POPE Study. Eur Respir J 2017:49(5):1601446.

31. Rich S, Dantzker DR, Ayres SM, Bergofsky EH, Brundage BH, Detre KM, Fishman AP, Goldring RM, Groves BM, Koerner SK. Primary pulmonary hypertension. A national prospective study. Ann Intern Med 1987;107(2):216-23.

32. Carpagnano GE, Radaeli A, Lacedonia D, Correale M, Carpagnano G, Palmiotti A, Barbaro MPF, Di Biase M, Brunetti N, Scioscia G, Malerba M. Exhaled Nitric Oxide and Exhaled Breath Temperature as Potential Biomarkers in Patients with Pulmonary Hypertension. Biomed Res Int 2018:7292045.

33. de Torres JP, Casanova C, Marín JM, Pinto-Plata V, Divo M, Zulueta JJ, Berto J, Zagaceta J, Sanchez-Salcedo P, Cabrera C, Carrizo S, Cote C, Celli BR. Prognostic evaluation of COPD patients: GOLD 2011 versus BODE and the COPD comorbidity index COTE. Thorax 2014;69(9):799-804.

34. Zbozinkova Z, Barczyk A, Tkacova R, Valipour A, Tudoric N, Zykov K, Somfay A, Miravitlles M, Koblizek V. POPE study: rationale and methodology of a study to phenotype patients with COPD in Central and Eastern Europe. Int J Chron Obstruct Pulmon Dis 2016;11:611-22.

\section{Supplemental Material:}

The online version of this article (doi: 10.5507/ bp.2020..035) offers supplemental material. 